\title{
Research on Evaluation of Technological Innovation Capability of Chinese Pharmaceutical Manufacturing
}

\author{
Zhen $\mathrm{Cao}^{1, *}$ \\ ${ }^{1}$ Beijing Jiaotong University, Major in Technical Economy and Management
${ }^{*}$ Corresponding author. Email: chengzi_982@163.com
}

\begin{abstract}
This article explores the technological innovation capability of China's pharmaceutical manufacturing industry from the perspective of macro-industry, and establishes an evaluation index system that includes three dimensions: technological innovation foundation, technological innovation input and technological innovation output. Through the principal component analysis of the data from 2009 to 2018 , it is found that the overall technological innovation capacity of the pharmaceutical manufacturing industry under the combined effect of the three dimensions has increased year by year, and the efficiency of technological innovation output has increased rapidly.
\end{abstract}

Keywords: pharmaceutical manufacturing, technological innovation capability

\section{INTRODUCTION}

Since the 1980s, my country's pharmaceutical industry has maintained rapid development and once became the fastest growing industry in the national economy. It is expected that sales revenue in 2020 will reach 950.4 billion yuan. As people pay more attention to their own health, the status of my country's pharmaceutical industry in the national economy has gradually improved; the aging degree has intensified, and higher requirements have been placed on the pharmaceutical industry and its products; emergencies in the process of globalization, Public events, such as the trade war and the COVID-19 epidemic, have brought new challenges to the pharmaceutical industry. In the development of my country's pharmaceutical industry, problems such as overcapacity of low-quality products and serious product homogeneity have appeared, and the scale of my country's pharmaceutical industry will continue to expand in the next two decades.

In order to realize the long-term and virtuous circular development of China's pharmaceutical manufacturing industry, technological innovation plays an important role in it. Relying on the high-efficiency utilization of resources, the multiplier increase in output value, and the added value of products, the pharmaceutical technology innovation ability not only meets the health needs of the people, but also continues to push the pharmaceutical manufacturing industry out of the "smile curve" trough. The evaluation and research on its technological innovation capabilities will help to better understand the current status and development potential of the industry, strengthen the strength and innovation capabilities of my country's pharmaceutical manufacturing industry, and provide a reference for long-term development.

\section{RESEARCH STATUS}

Scholars have studied innovation for a century from 1912 to the present, but the research on technological innovation capability is relatively late. Through combing domestic and foreign literature, it is found that the research probably started in the 1980s. D.L.Barton (1992) believes that the core of technological innovation capabilities should include employees who have mastered core knowledge and technology, technology and management systems, and corporate core values [1]. Edward (1997), from the perspective of organizational behavior, believes that the technological innovation capability of an enterprise is the ability of an enterprise to combine a series of complex features in an organization in order to facilitate and support the implementation of an organization's technological innovation strategy [2]. The concept of technological innovation capability was first proposed in China in the study of macro-science and technology policies. Through combing the literature, it is found that domestic scholars mostly conduct research from the perspective of the whole process of technological innovation capability. Fu Jiaji (1998) believes that the composition of technological innovation capability includes six aspects: innovation input, ability 
to manage innovation activities, innovation tendency, research and development capabilities, manufacturing and marketing [3]. Xu Qingrui and Wei Jiang (2008) believe that the technological innovation capability of an enterprise is a combination of a series of capabilities with integral functions, including the ability to support product and process innovation, the ability to support the enterprise's strategic innovation, and so on [4]. Wang Hongqing (2017) further expanded the composition of technological innovation capabilities, thinking that the overall system capabilities of an enterprise constitute the technological innovation capabilities of an enterprise. [5].

Based on the industry itself, this article believes that technological innovation is a process of opening up new markets and applying research results to the market to generate profits. The technological innovation capability is the dynamics of mastering and using many innovative resources. A synthesis of the required capabilities in the process of technological innovation is the result of the interaction and mutual influence of many factors.

\section{CONSTRUCTION OF EVALUATION INDEX SYSTEM}

\subsection{Theoretical basis}

Scholars at home and abroad have made many attempts to study the evaluation index of technological innovation capability, but there is still no complete evaluation index system. Hill (1994) proposed four indirect indicators to measure technological innovation capabilities [6]. Clark (1997) believes that technological innovation capability can be measured from two aspects: product innovation capability and process innovation capability [7]. Product innovation capability is a comprehensive manifestation of a company's product manufacturing cycle, product development efficiency and comprehensive product quality, and process innovation capability is a company's production
Integration of process equipment development, smallscale trial production, and mass production capabilities. Zhao Zonggeng et al. (2005) constructed a high-tech industry technology innovation capability evaluation index system from the three dimensions of "innovative technology foundation, innovation transformation capability, and innovation economy support capability", which contains five elements [8]. Zhang Qiannan and Zhao Yulin (2007) constructed an evaluation of the technological innovation capability of high-tech industries consisting of three primary indicators of "technical innovation input capacity, technological innovation output capacity, and technological innovation support capacity" and 8 secondary indicators [9].

As far as the evaluation system of the technological innovation capability of the pharmaceutical manufacturing industry is concerned, Yang Junge, Ding Jinxi, etc. (2011) studied the overall innovation strength of the industry from the perspective of national policies, and used patent output as an observation variable [10]. Cao Xiangbo, Guo Xihong, etc. (2012) introduced risk management theory to the field of medical technology innovation for the first time, and measured it with patent information [11]. Xia Maosen et al. (2020) used R\&D stage input indicators, intermediate output, scientific and technological achievements transformation stage input indicators, and scientific and technological achievements transformation stage output indicators, and selected a weighted network DEA-SBM model for empirical research [12].

\subsection{Technical innovation evaluation indicators}

Based on the above research, this paper considers the characteristics of technological innovation process and the availability of data, and uses a three-dimensional indicator system of technological innovation foundation, technological innovation input and technological innovation output. A summary of the indicators selected in this article is shown in Table 1:

Table 1. Index summary

\begin{tabular}{|c|c|c|}
\hline & First-level index & Second-level index \\
\hline \multirow{3}{*}{$\begin{array}{l}\text { Evaluation Index System of } \\
\text { Technological Innovation } \\
\text { Capability of Pharmaceutical } \\
\text { Manufacturing (I) }\end{array}$} & $\begin{array}{l}\text { The basis of technological innovation } \\
\text { (F1) }\end{array}$ & $\begin{array}{c}\text { Number of scientific research institutions (X1) } \\
\text { Number of personnel in scientific research institutions (X2) } \\
\text { Full-time equivalent of R\&D personnel (X3) } \\
\text { Number of newly started projects (X4) }\end{array}$ \\
\hline & $\begin{array}{l}\text { Technological innovation investment } \\
\text { (F2) }\end{array}$ & $\begin{array}{c}\text { Expenditure of scientific research institutions (X5) } \\
\text { Expenditure for technological transformation (X6) } \\
\text { New product development expenditure (X7) } \\
\text { R \& D Funds inner Expenditure (X8) } \\
\text { Investment in fixed assets (X9) }\end{array}$ \\
\hline & Technological innovation output (F3) & $\begin{array}{c}\text { Number of patent applications }(\mathrm{X} 10) \\
\text { Number of valid invention patents }(\mathrm{X} 11) \\
\text { New product sales revenue }(\mathrm{X} 12) \\
\text { Project completion rate }(\mathrm{X} 13) \\
\text { Main business income (X14) } \\
\text { Total profit (X15) }\end{array}$ \\
\hline
\end{tabular}




\section{EVALUATION OF TECHNOLOGICAL INNOVATION CAPABILITY}

\subsection{Data sources}

According to the principle of the availability of analytical data, this paper selects the relevant data from the 2009-2018 "China High-tech Industry Statistical Yearbook" as observational values, and the missing values from 2017-2018 are supplemented from the "China Science and Technology Statistical Yearbook".

\subsection{Evaluation of technological innovation capability based on principal component analysis}

This article uses Excel2013 and SPSS26.0 for data sorting, principal component analysis and related chart drawing. First test the validity of the research data: the KMO values of the three dimensions of the evaluation system's technological innovation foundation, technological innovation input, and technological innovation output are $0.673,0.708$, and 0.724 respectively, which are all greater than the critical value 0.6 , and the significance of Bartlett's test is less than 0.05. The construction validity is good, and further principal component analysis can be performed. This article selects the eigenvalues in the total variance interpretation table whose cumulative contribution rate is greater than $80 \%$, and divides the principal component data in the principal component loading matrix by the square root of the eigenvalue in turn to obtain each principal component coefficient, and then multiplies it by the standardized variable. Finally, the three-dimensional function expression of technological innovation in the pharmaceutical manufacturing industry is obtained by sorting out. After data sorting, the expression is as follows:

Technical innovation basis:

$\mathrm{F} 1=0.508 \times 1+0.520 \times 2+0.495 \times 3+0.476 \times 4$

Investment in technological innovation:

$\mathrm{F} 2=0.481 \times 5+0.232 \times 6+0.487 \times 7+0.492 \times 8+0.485 \times 9(2)$

Technological innovation output:

$\mathrm{F} 3=0.396 \quad \mathrm{X} 1+0.424 \quad \mathrm{X} 11+0.428 \quad \mathrm{X} 12+0.362 \quad \mathrm{X} 13+0.412 \quad \mathrm{X} 14+0.424 \quad \mathrm{X} 15$ (3)

On the basis of the calculated three-dimensional function formula, the standardized data is brought in, and the three-dimensional scoring table of technological innovation in the pharmaceutical manufacturing industry is obtained, as shown in Table 2:

After obtaining Table 2, the principal component analysis is performed on the data again, and the expression of the overall technological innovation capability function of China's pharmaceutical manufacturing industry is obtained. After the validity test, the KMO value of the three-dimensional data is 0.703 , which is greater than the critical requirement of 0.6 , and the Bartlett test significance is less than 0.05 , which all meet the requirements.

Table 2. KMO and Bartlett's Test

\begin{tabular}{ccc}
\hline \multicolumn{3}{c}{ KMO and Bartlett's Test } \\
\hline \multicolumn{3}{c}{ KMO Measure of Sampling Adequancy } \\
Approx. Chi- & .703 \\
Bartlett's Test of Sphericity & $\begin{array}{c}\text { Square } \\
\text { df }\end{array}$ & 51.260 \\
& Sig. & .000 \\
\hline
\end{tabular}

Once again the principal component analysis, the expression of the overall strength function of technological innovation in the pharmaceutical industry is also listed. Formula of technological innovation strength of pharmaceutical manufacturing industry:

$$
\mathrm{I}=0.580 \mathrm{~F} 1+0.576 \mathrm{~F} 2+0.577 \mathrm{~F} 3
$$

Incorporating the standardized data into the formula, the score table for the overall strength of technological innovation as shown in Table 4 is obtained.

Table 3. Three-dimensional score

\begin{tabular}{cccccc}
\hline \multirow{3}{*}{ Results } & 2009 & 2010 & 2011 & 2012 & 2013 \\
\cline { 2 - 6 } & -1.384 & -1.543 & -0.904 & -0.322 & 0.068 \\
\cline { 2 - 6 } & 2014 & 2015 & 2016 & 2017 & 2018 \\
\cline { 2 - 6 } & 0.372 & 0.622 & 0.860 & 1.006 & 1.226 \\
\hline
\end{tabular}

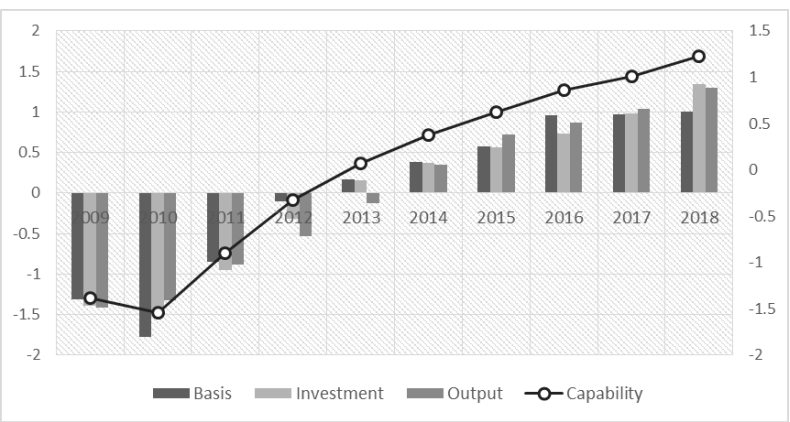

Figure 1 Overall strength trend

In order to understand the trend of medical technology innovation from 2009 to 2018, this article summarizes Table 2 and Table 4, technical innovation foundation, technical innovation input, technical innovation output, and technical innovation overall strength score scoring table, and draws a combination chart of the overall technical strength trend of the pharmaceutical industry(Figure 1).

\section{CONCLUSIONS AND RECOMMENDATIONS}

Based on the foregoing research on the evaluation of technological innovation capabilities, the following conclusions are drawn: 
First, the overall technological innovation strength of the national pharmaceutical manufacturing industry has steadily improved. As shown by the broken line representing the overall innovation strength in Figure 1, the innovation strength of my country's pharmaceutical manufacturing industry is showing a significant upward trend. According to the score table in Table 4, the overall technological innovation strength score of my country's pharmaceutical manufacturing industry has increased from -1.384 in 2009 to 1.226 in 2018. Both graphs and data directly reflect the steady improvement of the overall technological innovation strength of my country's pharmaceutical industry.

Second, the overall technological innovation strength of the pharmaceutical manufacturing industry is affected by various factors. From the function expression (4), it can be seen that the three dimensional weights of technological innovation foundation (0.580), technological innovation input (0.576), technological innovation output (0.577) have a positive effect on the improvement of the overall technological innovation strength of the pharmaceutical industry. As shown in Figure 1, the output efficiency of technological innovation has increased rapidly. It can be seen that the output advantages of the pharmaceutical manufacturing industry are gradually revealed in the stage of achievement transformation.

Finally, with the successive introduction of relevant scientific research and innovation policies, my country's pharmaceutical manufacturing industry has developed rapidly. The improvement of the innovation capability of the pharmaceutical manufacturing industry needs to be carried out from multiple angles and aspects: focus on the foundation of technological innovation and provide practical guarantee for innovation; increase investment in scientific research funds to inject vitality into innovation; improve the efficiency of technological innovation output and maintain the foundation of research and development advantages Promote the transformation of results, and finally realize the accumulation of scientific research quality.

\section{REFERENCES}

[1] D.L.Barton, Core Capability \& Core Rigidities: A Paradox in Managing New Product Development, Strategic Management, 1992:52-78. DOI: 10.1016/0024-6301(93)90313-5.

[2] Edward McDonough, Strategic management of technology and innovation, The Journal of Product Innovation Management, 1997,14(6). DOI:10.1016/S0737-6782(97)90049-7.

[3] Fu Jiaji, Technology Innovation. [M]. Beijing: Tsinghua University Press, 1998.
[4] Wei Jiang, Xu Qingrui, The concept, structure, measurement and evaluation of enterprise innovation ability, Scientific Management Research, 1995,(5). DOI:10.19445/j.cnki.15$1103 / \mathrm{g} 3.1995 .05 .013$.

[5] Wang Hongqing, Hou Yi, Research on the Evaluation of Technology Innovation Capability of China's High-tech Industry. Forum on Science and Technology in China, 2017(03): 58-63. DOI: 10.13580/j.cnki.fstc.2017.03.008.

[6] R Hill, Towards the Fifth-Generation Innovation Process, International Marketing Review, 1994 (1). DOI:10.1108/02651339410057491.

[7] K Clark, Implementing Structured Software Methodologies: a Case of Innovation in Process Technology, Interfaces, 1987, 17(3). DOI:10.1287/inte.17.3.6.

[8] Zhao Zonggeng, Wu Guowei, Dong Hui, etc. Research on the Evaluation Index System of Technological Innovation Capability of High-tech Industry. Hebei Industrial Science and Technology, 2005(3). DOI: CNKI:SUN:HBGY.0.2005-02-001.

[9] Zhang Qiannan, Zhao Yulin. An Empirical Analysis of the Technological Innovation Ability of High-tech Industry, Industrial Technology Economy, 2007 (4). DOI: CNKI:SUN:GHZJ.0.2007-04-005.

[10] Yang Junge, Ding Jinxi, Shao Rong. International Comparison of Incentive Policies for Biomedical Technology Innovation Research, China Medical Herald, 2011, 8(3): 6-8. DOI:CNKI:SUN:YYCY.0.2011-03-006.

[11] Cao Xiangbo, Guo Xihong, Qu Jiayi, et al. Evaluation of the effect of patent service intervention for technological innovation risk management, Journal of Information, 2012, 31(6): 35-37,74. DOI:CNKI:SUN:QBZZ.0.2012-06-008.

[12] Xia Maosen, He Qingguang, Jiang Lingling. Evaluation of the technological innovation capability of the pharmaceutical manufacturing industry, Statistics and Decision, 2020, 36(18). DOI:10.13546/j.cnki.tjyjc.2020.18.040. 